\title{
David L. Kleinberg: in memoriam
}

\section{7-2017}

(C) Springer Science+Business Media New York 2017

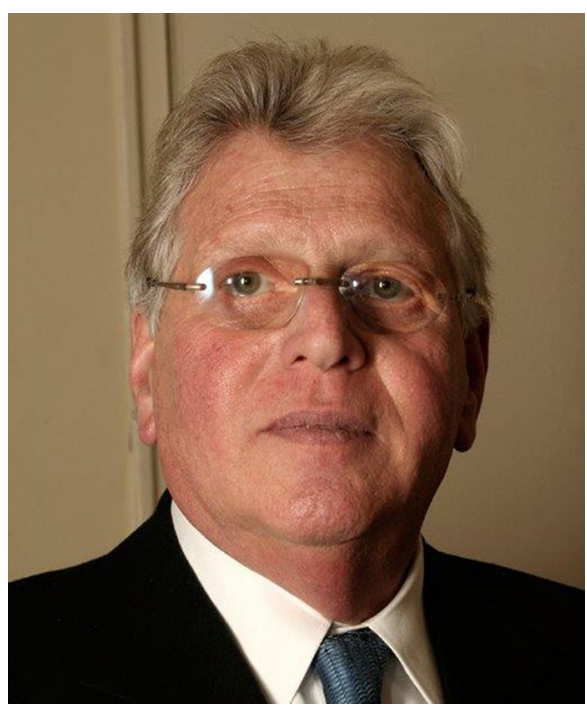

Dear friends,

Since last Friday January 27 we are all more alone. Our friend David passed away leaving all of us shocked and incredulous.

David L. Kleinberg was Professor of Medicine and Director of the Neuroendocrine Unit at New York University School of Medicine, New York, NY, and Consultant at the Veterans Affairs, New York Harbor Health Care System, NY. David graduated from the University of Miami Leonard M Miller School of Medicine and completed his residency at New York Presbyterian. He was a prominent member of the international endocrine community having served on the editorial board for the Journal of Clinical Endocrinology and Metabolism, Pituitary and Endocrine Reviews. He coauthored the anterior pituitary chapter in the 10th through 13th Editions of Williams Textbook of Endocrinology.

David was a brilliant researcher having shown that prolactin and growth hormone were separate molecules in humans and highly contributed to the understanding of the reciprocal role of growth hormone and prolactin in mammary development. He was currently evaluating the potential of IGF-I inhibition in breast cancer prevention. As a clinician he was much appreciated for his great knowledge in the pituitary field. I personally remember his expert contribution to the preparation of the clinical guidelines on hyperprolactinemia of The Pituitary Society. His article on the pathophysiology of galactorrhea remains the standard work on that subject. He was a recognized authority on growth hormone deficiency and the treatment of acromegaly and other pituitary tumors. David was past President of The Pituitary Society and currently Secretary-Treasurer of our Society.

But what I want to remember besides these formal although essential roles is that David was the heart and soul of our Society. Under his leadership the Society flourished and became what is now: the home of all pituitary doctors! David worked for decades to build up the Society as an organized body supporting ambitious initiatives to help and benefit patients with pituitary diseases. I personally discussed with him many of these projects and what always was striking me was his continuous effort to find ways to improve the quality of pituitary disease management around the world and to improve the lives of pituitary patients. Last but not least David was a great man. I had the honor to be one of his friends and I want to remember him as a charming gentleman who always had a smile and a word of support for everybody particularly when things were not going well. He was a natural leader and a master of style and life for many of us who had the unique opportunity to share part of their life with him.

We will miss your guidance a lot dear David!

Andrea Giustina, MD

President

The Pituitary Society 